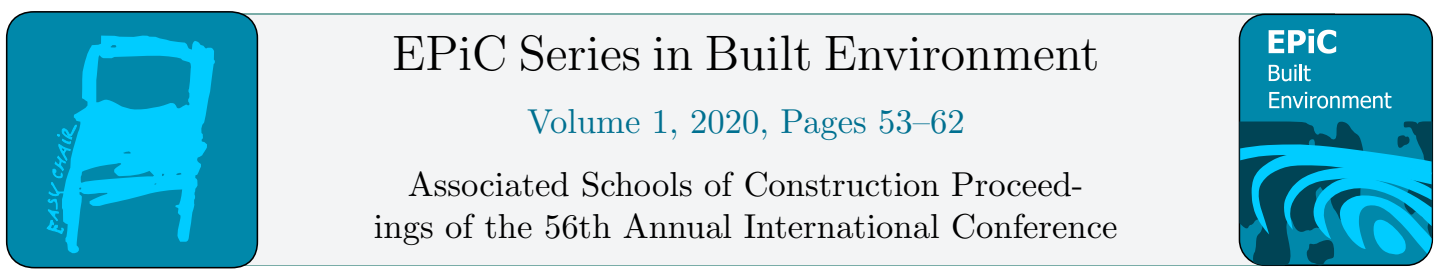

\title{
Integrating Social Media Platforms in Construction Education to Increase Student Engagement
}

\author{
Piyush Pradhananga, Mohamed EIZomor, Ph.D., Arif Mohaimin Sadri, Ph.D., and Nipesh \\ Pradhananga, Ph.D., P.E. \\ Florida International University \\ Miami, Florida
}

\begin{abstract}
This study evaluates the integration of Social Media (SM) as an informal pedagogical tool to support STEM, by fostering engagement and increasing interactional competency and collaborative skills. Construction engineering education has been plagued with low engagement levels partially due to its timeworn pedagogical means and ineffective use of technology. SM platforms are convenient, and effective informal educational means that encourage engagement and interactions between peers. Nowadays, construction programs are shifting to online educational forms and this research is geared to understand the interactions between student bodies within different instructional forms. This study focuses on assessing the impact of SM related activities on students' engagement and professional skills by integration it within Construction Management (CM) courses. The novel contribution of this research is to study the benefit of integrating SM not only for increasing student engagement but also effective communication between online and face to face CM students as well as their soft skill development. This research initiative presents paired t-test and box plots with line plots from pre and post-course surveys of 75 students. Finally, this paper highlights the challenges and lessons learned along with recommendations for transferring this pedagogy to other institutions.
\end{abstract}

\section{Key Words: Social Media, Engagement, Construction Management, Professional Skills}

\section{Background and Motivations}

The President's Council of Advisors on Science and Technology projected a required increase of one million STEM graduate students in the next decade and advocated to develop innovative teaching practices, which improves student engagement as well as performance and meets this goal. Also, there is an urgent need to bolster the competitiveness of STEM fields in the United States, which necessitates improving the available pedagogies that support teaching and training (Elzomor \& Youssef, 2019). STEM courses are primarily lecture-based that lack interactive learning environments and place students in a more passive role without providing enough opportunities to be creative and engage with peers (Wells, 2008). As such, technical issues related to ensuring innovative pedagogies that train and support STEM students have escalated, such as the integration of STEM courses positioned in upper and lower divisions to benefit student learning and training (ElZomor et al. 2016). However, student engagement suffers from the challenges associated with such logistics, which is also evident from the 
lower number of STEM graduates in recent years (ElZomor et al. 2018). Therefore, it has become critical to address student engagement by integrating real-world contexts to develop more challenging examples that relate their coursework to real-life experiences (Brzozowy et al., 2017). Another means to couple classrooms with real-world exposure is the use of available technological tools (i.e., Social Media), thus connecting students with their classroom peers as well as the entire world (Moolenaar, 2012). Social Media is a free platform that is easily accessible where students could immerse themselves in actual problems while sharing, interacting and discussing solutions with each other as well as professionals. However, the integration of Social Media in STEM education is yet to be fully implemented in course syllabi.

Social Media, a technological tool that includes different social networking platforms (Facebook, Twitter, LinkedIn, Instagram, etc.), is used by more than 40 million students ( Lenhart and Purcel 2010). Recent studies have shown how to leverage social media data to quantify social influences using network science principles and data-driven method (Sadri et al. 2018). The accessibility of Social Media tools through a laptop, cell phone, or tablet makes it convenient and universal; thus, the number of students using Social Media is on the rise significantly (Liu, 2010). Social Media is an effective platform for students as it provides connections to current and former peers, facilitates emotional support and recommends creative activities (Cheston et al., 2013). Despite such benefits, the integration of Social Media in education faces several technical obstacles, availability of interest, and privacy issues due to which effective strategies need to be developed to integrate Social Media in STEM disciplines efficiently, thus enhancing students' learning and engagement (Ivala \& Gachago, 2012).

Research studies in recent years explored an effective method of integrating Social Media platforms as an informal learning environment in non-STEM fields such as learning new languages, facilitating social support, and developing innovative literacies (Greenhow \& Askari, 2017). These studies demonstrated that integrating Social Media in informal learning environments improves communication between students and/or teachers, engagement in creative activities and a better understanding of the course materials. Other advantages of integrating Social Media are the flexibility of following course lessons in any place and during any time and ideally engaging in course materials by sharing opinions and discussing problems with peers (Rutten \& Vandermeersche, 2013). The use of Social Media has also been introduced in the medical field, where the integration of Social Media tools increased opportunities for cooperative and active learning (Cheston et al., 2013). Recent studies on infrastructure resilience and sustainability in the engineering domain have shown how to quantify social influence through Social Media interactions systematically. As a next step, this study is gathering data to explore the application of Social Media platforms in STEM education and to evaluate whether their integration enhances student professional skills and retention. Analyzing the retention and soft skills of students has been postponed to future studies, as the authors need to gather additional data.

\section{Methodology}

A pre- and post-course questionnaire survey was conducted at the beginning and end of the fall 2018 semester in three STEM classes with three different instructional forms (e.g., fully online, face-to-face, and hybrid). The data collection is considered a pilot study to evaluate the impacts of SM in a CM program. The three initial experimental courses are Sustainability, Construction Materials/Methods, and Automation in Construction representing a lower, middle and higher-level students in a minorityserving institution where about $60 \%$ of the students are Hispanic, making the university one of the top granters of bachelor's degree to Hispanic undergraduates. The diversity of students in this university provides an excellent opportunity to understand the effectiveness of integrating SM platforms to support STEM course deliverables from different perspectives including minorities. 
The STEM courses Sustainability, Materials, Methods and Equipment, and Automation in Construction each had 25, 35, and 15 pre-course responses, respectively. In total 75 students responded to the postcourse survey, while all 75 students in three courses responding to the pre-course survey had a matching post-course response. Students were asked to create a unique unanimous personal identification code (first four letters of the name of the city where you were born + last four digits of students' phone numbers) to match students' pre- and post-responses. Also, the survey collected personal, demographic and background information through six categories: Military status (i.e., Veteran, Non-Veteran), Gender (Male, Female), Race (African American, Asian, White, Hispanic, other), Employment status (i.e. Employed, Unemployed), and finally whether the student uses Social Media or not.

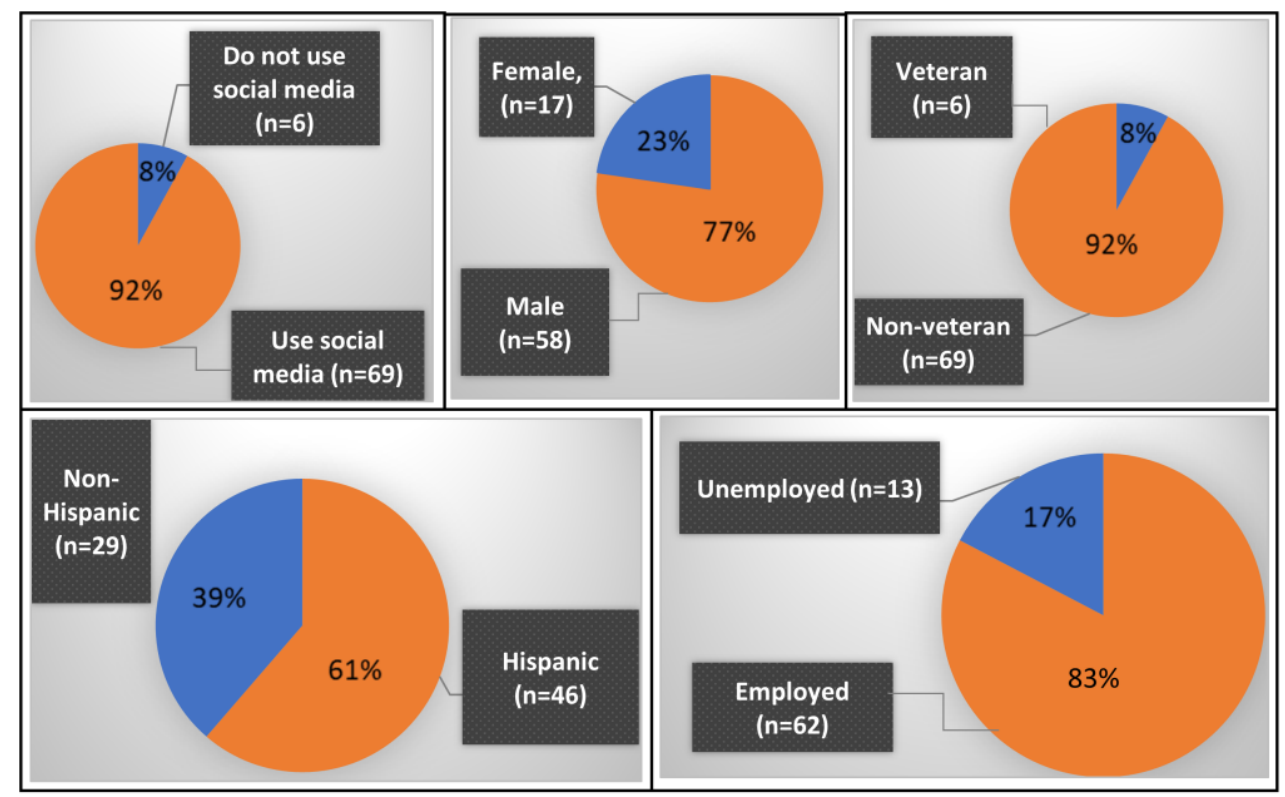

Figure 1: Student responses based on personal, demographic and background information $(\mathbf{N}=75)$

The questionnaire in the survey is related to the students' different skill levels, academic goals, and their anticipation to integrate Social Media platforms in courses. The research was based on surveying students twice a semester to understand/evaluate the impact of Social Media activities/assignments that were introduced during the semester. At the beginning of the term, a pre-course survey gathers information related to student's study habits, self-evaluation of current professional skills, as well as information about average Grade in High School, Effectiveness of Social Media for learning STEM and Effectiveness of Social Media in supporting overall class deliverables. Instructors included course learning outcome statements in their syllabi, which can be evaluated through Social Media, especially that some of those outcomes do not need calculations but rather require an overall understanding of concepts that can be represented by a tweet/post or a one-minute video. During the semester, students were required to use twitter to submit their homework as well as to post comments about their understandings of class materials, which were graded towards their course participation. For example, in the substantiality course, the instructor provoked general questions that relate to class materials and students were asked to tweet about them; some of these questions were: (1) what is not sustainable about their homes; (2) how our infrastructure can be more sustainable; and (3) what the correlations 
between sustainability from social, economic and environmental perspectives are. Another example from a previous implementation was in an Ethics course, where students posted an image on Instagram that responds to: what is ethics from an engineering perspective and how would a project manager's office include unethical/biased resources. By the end of the semester, the students complete a postcourse survey that addresses the same questions.

The pre- and post-course surveys in this study are also used to evaluate the effectiveness of integrating Social Media platforms in STEM courses. The responses from pre- and post-course surveys were matched and compared using paired t-tests in SPSS. A paired t-test is a parametric test in which assumptions are made about the parameters of the distributed population from which a sample has been drawn. The basic statistical procedure for conducting a paired $\mathrm{t}$-test includes determining whether the mean difference between two sets of observations, for example, individual scores in each of the survey sets, is equal to zero or not. As such, for paired t-test in SPSS, a confidence interval of $95 \%$ is set for the analysis.

\section{Discussion and Results}

To identify the effectiveness of Social Media platforms in learning and supporting overall class deliverables, a paired t-test was conducted using pre- and post-course survey data. For better comprehension of students' professional skills, box plots with line plots were made using R-studio which provided an understanding of how the comparable results are spread out. The rectangular box between two whiskers consists of the dark horizontal line representing median value and the edges of the box represent $1^{\text {st }}$ quartile and $3^{\text {rd }}$ quartile. The interpretation of the three courses' two paired t-test and box plots are described below:

\subsection{Effectiveness of Social Media}

\section{Course 1: Sustainability}

From the assessment of differences between the pre- and post-course surveys for the sustainability course (Table 2), it could be observed that students, in general, have found a Social Media platform to be effective for learning as well as in supporting overall class-deliverables. It can be concluded that the $\mathrm{P}$-value is greater than 0.05 for both variables indicating there is no significant difference in means of pre- and post-course results.

Table 2: Sustainability Course: Paired t-test analysis for the Social Media Platforms' effectiveness

\begin{tabular}{cccccc}
\hline S.N. & Variables & $\begin{array}{c}\text { Absolute } \\
\text { Mean } \\
\text { Difference }\end{array}$ & $\mathrm{t}$ & $\begin{array}{c}\text { Degree } \\
\text { of } \\
\text { Freedom }\end{array}$ & $\begin{array}{c}\text { P- } \\
\text { Value }\end{array}$ \\
\hline 1. & $\begin{array}{c}\text { Effectiveness of Social Media Platforms } \\
\text { for Learning STEM course }\end{array}$ & .04 & .106 & 24 & .916 \\
\hline 2. & $\begin{array}{c}\text { Effectiveness of Social Media Platforms in } \\
\text { supporting overall class deliverable }\end{array}$ & .250 & -.743 & 23 & .465 \\
\hline
\end{tabular}

\section{Course 2: Construction Materials/Methods}


From the assessment of differences between the pre- and post-course surveys for Construction Materials/Methods (Table 3), it could be observed that students have found a Social Media platform to be effective for learning as well as in supporting overall class-deliverables. This has been similar to the results of the Sustainability course. The P-value for both categories of the effectiveness of the Social Media platform is greater than 0.05 . Therefore, there is no significant difference in means of pre- and post-course assessments.

Table 3: Construction Materials Course: Paired t-test analysis for the Social Media Platforms' Effectiveness

\begin{tabular}{cccccc}
\hline S.N. & Variables & $\begin{array}{c}\text { Absolute } \\
\text { Mean } \\
\text { Difference }\end{array}$ & t & $\begin{array}{c}\text { Degree } \\
\text { of } \\
\text { Freedom }\end{array}$ & $\begin{array}{c}\text { P- } \\
\text { Value }\end{array}$ \\
\hline 1. & $\begin{array}{c}\text { Effectiveness of Social Media Platforms } \\
\text { for Learning STEM course }\end{array}$ & .1333 & .695 & 14 & .499 \\
\hline 2. & $\begin{array}{c}\text { Effectiveness of Social Media Platforms in } \\
\text { supporting overall class deliverable }\end{array}$ & .0667 & .202 & 14 & .843 \\
\hline
\end{tabular}

\section{Course 3: Automation in Construction}

Corresponding to the other two courses, (table 4) shows that Social Media platform is effective for learning as well as in supporting overall class-deliverable. In overall analysis, the P-value for both categories of the effectiveness of the Social Media platform is greater than 0.05 . Therefore, there is no significant difference in means of pre- and post-course assessments.

Table 4: Automation in Construction: Paired t-test analysis for the Social Media Platforms' effectiveness

\begin{tabular}{cccccc}
\hline S.N. & Variables & $\begin{array}{c}\text { Absolute } \\
\text { Mean } \\
\text { Difference }\end{array}$ & t & $\begin{array}{c}\text { Degree } \\
\text { of } \\
\text { Freedom }\end{array}$ & $\begin{array}{c}\text { P- } \\
\text { Value }\end{array}$ \\
\hline $1 . \quad \begin{array}{c}\text { Effectiveness of Social Media Platforms } \\
\text { for Learning STEM course }\end{array}$ & .2857 & -1.575 & 34 & .124 \\
\hline $2 . \quad \begin{array}{c}\text { Effectiveness of Social Media Platforms } \\
\text { in supporting overall class deliverable }\end{array}$ & .0286 & .106 & 34 & .916 \\
\hline
\end{tabular}

Additionally, the effectiveness of social media platforms (e.g., Twitter) were also represented with box plots for understanding the overall changes in the perception of social media use based on students' self-ratings. The authors integrated a social media platform (twitter) in three different construction management courses and were provided an activity using social media. For instance, they were asked to post an image or a video that provoked construction related sustainable questions along with the use of hashtags such as \#Coursenumber, \#sustainability and, \#construction. The authors assessed the effectiveness of social media based on a five-point Likert scale from 1 (Not at all) to 5 (very effective). The median students' self-evaluation (shown as a thicker line in figure 3 ) indicates that at the start of the course, the median student rated social media moderately effective in both learning and supporting overall deliverables, as shown in Fig. 4. 


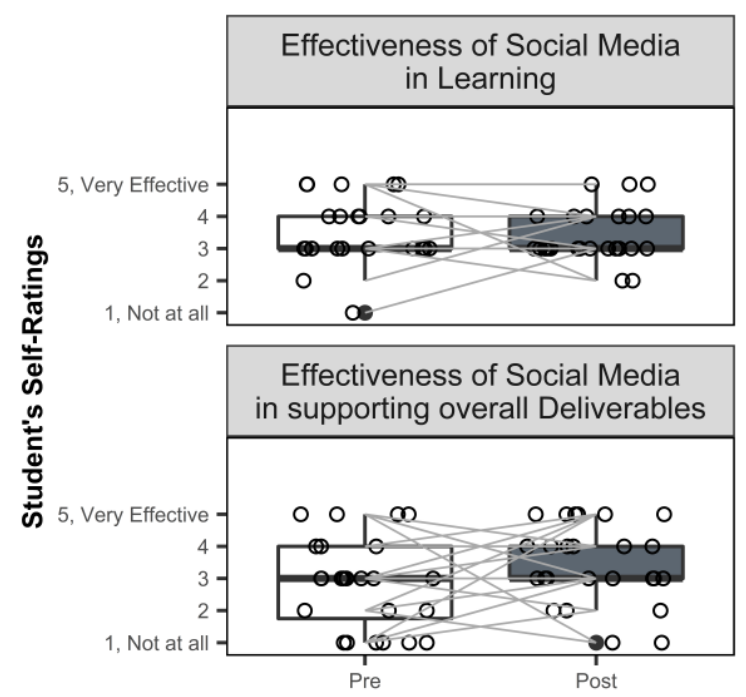

Figure 2: Students' pre and post-course ratings on the effectiveness of social media

Fig. 2 demonstrates that at the end of the course, the median student rated the effectiveness of social media as effective with one level increase in rating for supporting overall deliverables, probably because its increased peer discussions and sharing of ideas and understandings. While for the effectiveness of social media in learning, the same rating of students was observed in post-course survey, probably because these more advanced students were more productive in a face to face class and an online class.

\subsection{Students' Professional skills}

This paper evaluated different professional development skills which can be categorized into two categories: (1) Interactional Competency Skills and; (2) Collaboration Skills. The study only focused on the elements of professional development skills that are affected by the integration of social media platforms in construction management courses. For instance, interactional competency skills such as technical communication is a type of professional development skills which is likely developed by students throughout the course. On the other hand, interdisciplinary skills are not likely to develop during students' course activities and are instead developed during in-course communication.

\subsubsection{Interactional Competency Skills}

The authors focus on three interactional competence (IC) skills which include: (1) technical communication skills (i.e., talking with someone from within your field of expertise); (2) Interdisciplinary communication (i.e., talking about technical details with someone from outside of your field of expertise) and; (3) Understanding the perspectives of different fields on a problem. Students were assessed for their skills in IC on the five-point scale: 1 (no knowledge), 2 (beginner: some experience or basic knowledge), 3 (proficient: can utilize at a satisfactory level), 4 (advanced: can utilize 
better than most), and 5 (expert: can utilize with a superior level of skill and teach to others). The survey results indicated that students assessed more growth for themselves and reported a gain in confidence in technical communication skills. The median students' self-reported responses (shown as a thicker line in figure 3) indicate that at the start of the course, the median student rated herself/himself as a proficient in technical communication skills.

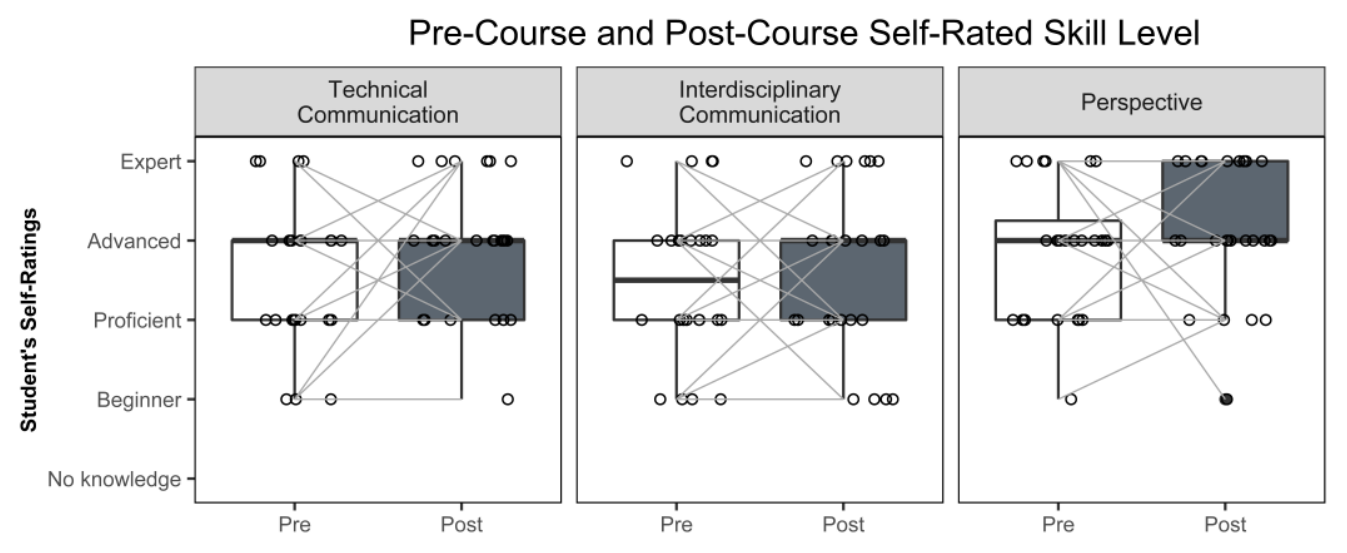

Figure 3: Students' pre- and post-course self-rated skill level in three CM courses

Fig. 3 demonstrates that at the end of the course, the median student rated himself/herself as advanced in technical communication skills, indicating a one-level increase over the semester, possibly due to ease of communication through social media platforms. However, students reported the same skill level in interdisciplinary communication (i.e., talking about technical details with someone from outside of your field of expertise) and understanding the perspectives of different fields on a problem at the start and end of the course. Perhaps this was because these more advanced students were already enrolled in an interdisciplinary course.

\subsubsection{Confidence in Collaborative Skills}

Collaborative skills developed by students through integration of social media platforms include: (1) providing feedback to team members, (2) receiving criticism from team members, (3) communicating technical information to people within their field of expertise and, (4) communicating technical information to people outside their field of expertise (technical interdisciplinary communication). This was assessed based on a five-point Likert scale from 1 (Not at all confident they could do this) to 5 (extremely confident they could be highly successful and could teach others to be successful). Students' self-reported confidence in collaborative skills at the start and end of the course for all the students are represented in the form of box plots with line plots (see figure 2). The results obtained for the median student indicates that there is moderate gain in confidence in collaboration skills in the post-course survey. Mean and median differences show that students developed more confidence in their technical interdisciplinary communication than their intradisciplinary communication, which demonstrated little change, if any, between pre and post-course confidence ratings. However, students reported the same skill level in providing feedback to team members and receiving criticism from team members at the start and end of the course, perhaps because these more advanced students were already enrolled in a constructive criticism course. 


\section{Confidence in Collaborative Skills}

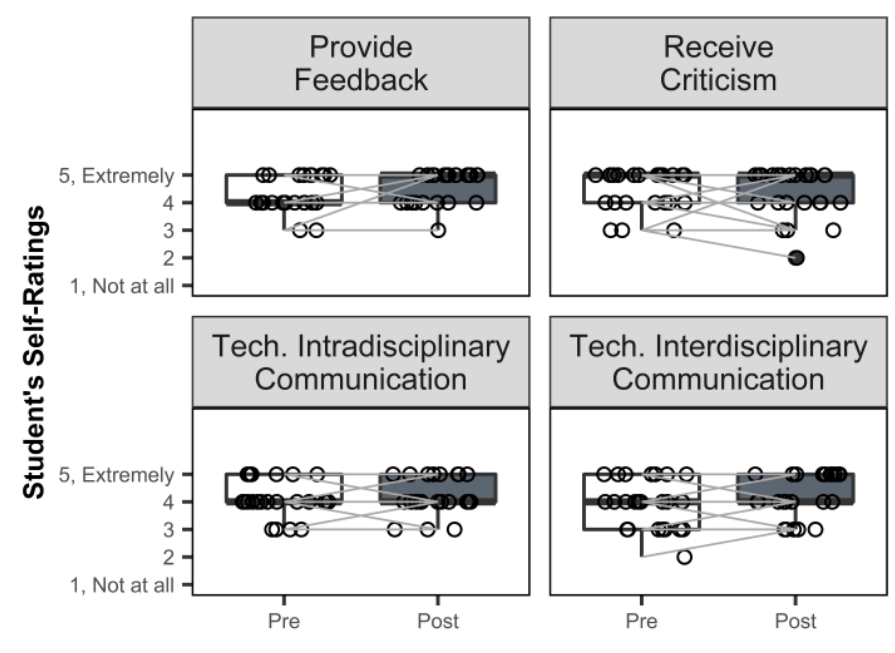

Figure 4. Students' pre and post-course confidence in collaborative skills in three construction management courses

\section{Challenges, Lessons Learned, and Recommendations}

This implementation requires courses to be offered during the same semester and their assignments to be connected so that students relate to each course's learning outcomes. The instructors must dedicate time to planning the logistics, aligning the syllabi, and homework projects. Any overlap between courses reflects real life, so faculty must embrace how those overlaps can be utilized to correlate Social Media homework for the benefit of the students. A major concern was that one student was registered for two of the courses at the same time, yet the faculty decided to ask the student to conduct each course's deliverable separately.

Integrating such innovative technological tools that are engaging to learners not only creates a sense of appreciation and belonging but also provide real connections to the world. Students were able to connect to current issues outside academia through their engagement in Social Media. Further, Social Media helped students develop their research skills to gain additional insights on the topic before engaging in a Social Media activity. The flexibility that Social Media platforms provided in terms of connection with peers improved their teamwork skills and diversified their selections for team presentations while motivated them to engage in extracurricular construction issues. Additionally, students mentioned that Social Media supported their critical thinking skills, made the course more interesting and helped them retain the course materials more effectively.

It is challenging and critical for instructors to train students effectively in a course that has an outside component, especially that learners should differentiate between accurate and inaccurate information in the real-world. Hence, there should be a balance between face-to-face meetings and online activities to effectively utilize the benefits of integrating Social Media platforms in Construction. Future research should include more institutional paradigms that address collaborative/shared deliverables that open up more discussions between various disciplines. This approach has some limitation including privacy and 
finding a mutual platform for the whole class (Twitter, Facebook, Instagram, etc.). Therefore, although this framework creates a replicable pedagogy to develop professional skills in CM students, the scope of the data collection may be a little narrow as there remains challenges to track students beyond the semester especially due to conforming with FERPA. Furthermore, validating the efficient performance of CM students in the industry would require further study with an assessment plan designed to track these student's post-graduation.

\section{Conclusion}

This study evaluated the effectiveness of Social Media platforms in Construction Management courses with different instructional forms and divisions in the program by using pre-and post-course surveys. A paired t-test and box plot showed the effectiveness of Social Media platforms in enhancing the skills and increasing engagement and continued interest in Construction Management courses. Indeed, the integration of Social Media platforms positively impacted students which became possible through realworld exposure to issues in Construction education. Additionally, a student from all three courses (including Sustainability, Methods, Materials, and Equipment and Automation in Construction) improved their grades, which could be associated with exposure to more engaging and practical examples available in professional construction sites through Social Media platforms. Therefore, this study validates the positive impact of Social Media platforms on student performance at the end of the semester in comparison to the beginning. Future research should collect more comprehensive data and capture the actual Social Media online interactions to quantify the level of influence in construction learning in a versatile environment.

\section{References}

Amanda Lenhart, Kristen Purcel, A. S. and K. Z. (2010). Social Media and mobile Internet Use Among Teens and Young Adults (Vol. 01). Retrieved from http://pewinternet.org/Reports/2010/Social Media-and-Young-Adults.aspx

Brzozowy, M., Hołownicka, K., Bzdak, J., Tornese, P., Lupiañez-Villanueva, F., Vovk, N., ... Moussas, X. (2017). Making STEM education attractive for young people by presenting key scientific challenges and their impact on our life and career perspectives. INTED2017 Proceedings, 9948-9957. https://doi.org/10.21125/inted.2017.2374

Cheston, C. C., Flickinger, T. E., \& Chisolm, M. S. (2013). Social Media Use in Medical Education : A Systematic Review. Academic Medicine, 88(6), 893-901. https://doi.org/10.1097/ACM.0b013e31828ffc23

ElZomor, M., Mann, C., Doten-Snitker, K., Parrish, K., Chester, M. (2018). Leveraging Vertically Integrated Courses and Problem-Based Learning to Improve Students' Performance and Skills. Journal of Professional Issues in Engineering Education and Practice, 144(4), 04018009. https://doi.org/10.1061/(asce)ei.1943-5541.0000379

ElZomor, M., Parrish, K., Mann C. (2016). Positioning Students to Understand Urban Sustainability Strategies through Vertical Integration : Years 1 through 3 Positioning Students to Understand Urban Sustainability Strategies through Vertical Integration: Years one through three Abstract: Common. In ASEE's 123rd Annual Conference and exposition.

Elzomor, M., \& Youssef, O. (2019). Coupling Haptic Learning with Technology To Advance Informal STEM Pedagogies. American Society for Engineering Education.

Greenhow, C., \& Askari, E. (2017). Learning and teaching with social network sites: A decade of research in K-12 related education. Education and Information Technologies, 22(2), 623-645. https://doi.org/10.1007/s10639-015-9446-9 
Ivala, E., \& Gachago, D. (2012). Social media for enhancing student engagement: The use of Facebook and blogs at a University of Technology. Sajhe, 26(1), 152-166. https://doi.org/10.1080/00091380109601795

Liu, Y. (2010). Social Media Tools as a Learning Resource. Journal of Educational Technology Development and Exchange (JETDE), 3(1). https://doi.org/10.18785/jetde.0301.08

Moolenaar, N. M. (2012). A Social Network Perspective on Teacher Collaboration in Schools: Theory, Methodology, and Applications. American Journal of Education, 119(1), 7-39. https://doi.org/10.1086/667715

Rutten, K., \& Vandermeersche, G. (2013). Integrating Social Media in Education. Comparative Literature and Culture, 15(3).

Sadri, A. M., Hasan, S., Ukkusuri, S. V., \& Suarez Lopez, J. E. (2018). Analysis of social interaction network properties and growth on Twitter. Social Network Analysis and Mining, 8(1), 1-13. https://doi.org/10.1007/s13278-018-0533-y

Wells, J. G. (2008). STEM Education: The Potential of Technology Education. In 95th Annual Mississippi Valley Technology Teacher Education Conference. 